\title{
Fever with Rash is One of the First Presentations of COVID-19 in Children: A Case Report
}

This article was published in the following Dove Press journal:

International Medical Case Reports Journal

\section{Mohammad Reza Navaeifar (iD) \\ Mehrdad Poudineh Ghazaghi (iD) ${ }^{2}$ \\ Leila Shahbaznejad' \\ Hamed Rouhanizadeh ${ }^{3}$ \\ Mahnush Abutalebi \\ Mobina Ranjbar Varandi (D) ${ }^{2}$ \\ Mohammad Sadegh Rezai (iD) \\ 'Pediatric Infectious Diseases Research Center, Mazandaran University of Medical Sciences, Sari, Iran; ${ }^{2}$ Faculty of Medicine, Mazandaran University of Medical Sciences, Sari, Iran; ${ }^{3}$ Pediatric Department, Faculty of Medicine, Mazandaran University of Medical Sciences, Sari, Iran}

Correspondence: Mohammad Sadegh Rezai Bu-Ali Sina Hospital, Mazandaran University of Medical Sciences, Sari, Iran Email drmsrezaii@yahoo.com
Introduction: Clinical presentations of the severe acute respiratory syndrome coronavirus 2 (SARS-CoV-2) vary among patients, which make a confusing challenge for clinicians to diagnose the disease. While the disease is not rare, but the symptoms may be atypical in children.

Case Presentation: A 12-month-old boy with fever and rash without respiratory complaints at the onset of the disease presented to the hospital. His illness was then accompanied by severe anemia, hypoalbuminemia, hypoxemia, and pleural effusion. The nasopharyngeal swab polymerase chain reaction test was positive for the novel coronavirus. Despite primary normal lung imaging, the second imaging was typical for the disease on the third day of admission.

Discussion: Dermatologic manifestations of the novel coronavirus infection are not rare during the illness but rarely occur at the onset of the disease. Information about the cutaneous manifestations of SARS-CoV-2 and its time interval from the onset of the disease in children are not clear yet. Severe anemia, hypoalbuminemia, and pleural effusion are not reported as classic findings of the novel SARS-CoV-2. They may be considered as a consequence of the hyperinflammatory response or direct effect of the virus.

Conclusion: As a different manifestation of SARS-CoV-2, infected children may initially present fever and rash. More studies are needed to discover the cause of these complications. The correct answer may lead to better insight and more effective treatment.

Keywords: SARS-CoV-2, COVID-19, fever, rash, children

\section{Introduction}

Since December 2019, the severe acute respiratory syndrome coronavirus 2 (SARSCoV-2) infection has become a breathtaking challenge among healthcare providers and governments worldwide. In March 2020, the World Health Organization (WHO) announced a Pandemic situation, and until now, unfortunately, this pathogen has had thousands of victims infected and died. ${ }^{1}$

Mostly human coronavirus infections cause mild health issues; however, already two beta viruses from the same family of the novel coronavirus 2019 (COVID-19), including severe acute respiratory syndrome coronavirus (SARS) and middle east respiratory syndrome coronavirus (MERS) have emerged as fatal outbreaks worldwide. . $^{2,3}$

The clinical presentations of SARS-CoV-2 are different for various patients, which made its diagnosis a challenging task for healthcare providers. Fever, dry cough, dyspnea, myalgia, diarrhea, etc. are the most frequent presentations of the SARS-CoV-2. ${ }^{4}$ 
In children, it seems that the novel coronavirus mostly appears as a mild condition; however, in some cases, it may have fatal consequences. ${ }^{5-8}$

Although the dermatologic presentations are not rare in adults, some cutaneous lesions such as erythematous rash, widespread urticaria, and chickenpox-like vesicles are reported recently. ${ }^{6,9}$

There are some reports of simultaneous presentation of skin rash and SARS-CoV-2 in children, who are mostly reported as Hyper-inflammatory shock or Kawasaki disease. $^{10,11}$

The current study aimed to report an infant, firstly presented with fever and rash, subsequently accompanied by hypoalbuminemia, anemia, and respiratory distress with the diagnosis of COVID-19. To the best knowledge of the authors, it is the first report of this presentation in children with the novel coronavirus.

\section{Case Report Before Admission}

A 12-month-old boy was presented to the emergency department of Bu-Ali Sina hospital in Sari, north of Iran, in April 2020, with the chief complaint of fever and skin rashes.

Written informed consent was signed by the patient's parents to allow any case information and any accompanying medical images published. This report is a substudy of clinical and paraclinical characteristics of COVID-19 that is approved in the relevant university committee (ethical code IR.MAZUMS.REC.1398.7277).

Fever was begun 4 days before the admission and was 39-degree centigrade (measured using an axillary device at home).

On the second day of illness, the febrile child developed skin rashes starting from the soles symmetrically and ascending to the trunk, and finally, the face was engaged. Parents did not report any history of itching, pain, or burning sensation of the rashes. Besides, they declared no history of allergy to food, drugs, etc.

The vaccination was done completely according to Iran's national vaccination program. Developmental history revealed no problem. From the start of the illness course, parents reported that the child had a history of receiving azithromycin only in a single dose. Parents were nurses and were infected with the novel coronavirus during the past 20 days. They had direct contact with the child during their infection.

\section{The First Day of Admission}

Examination in the emergency room (ER) revealed an illappearing child with a 38.2 degrees centigrade axillary temperature. Blood pressure was 100/60 mm Hg. The pulse rate and respiratory rate were 98 and 22 per minute, respectively.

The dermatologic examination revealed erythematous maculopapular erythema multiform like targetoid rashes with faded centers on the trunk and lower extremities as well as erythematous patches on the face (Figure 1). The skin was mildly edematous but was not pruritus.

Palms and soles were involved, but mucosal membranes were spared (Figure 1F).

The oropharynx and tonsils were erythematous, but examination for lymphadenopathy indicated a negative result. No rhinorrhea and otitis was observed, but the child had mucopurulent discharge from the right eye, indicating conjunctivitis.

Intercostal retraction, tachypnea, and other signs of respiratory distress were not observed during the patient examination in the ER.

The child was admitted with suspicion of COVID-19 infection. Supportive care, including sufficient hydration and ceftriaxone (40 mg per $\mathrm{kg}$, every 12 hours), was administered.

A blood specimen was drawn for laboratory investigations, and Reverse-Transcription Polymerase Chain Reaction (RTPCR) was used for ruling in SARS-CoV-2 infection. The laboratory results are described in Table 1. RT-PCR from nasopharynx for COVID-19 (E gene) was positive.

The first-day admission chest X-ray and highresolution CT scan (HRCT) did not show any typical clue to SARS-CoV-2 infection.

\section{The Second Day of Admission}

The general health condition of the patient was deteriorated, edema progressed on extremities, and the child developed tachypnea, moderate stridor, intercostal retraction, and overall respiratory distress. The measured $\mathrm{O} 2$ saturation decreased down to $87 \%$ on room air, which indicated the necessity of oxygenation using a facial mask (5-8 liters per minute) and pediatric intensive-care unit admission.

Hydroxychloroquine (5 mg per kg Daily), syrup cetirizine (2.5 milliliters Daily), intravenous immunoglobulin (1 gram per $\mathrm{kg}$ ), zinc gluconate (20 mg Daily), albumin (1 gram per kg of $10 \%$ solution), and vitamin D (cholecalciferol 1000 IU orally Daily) were administered. 

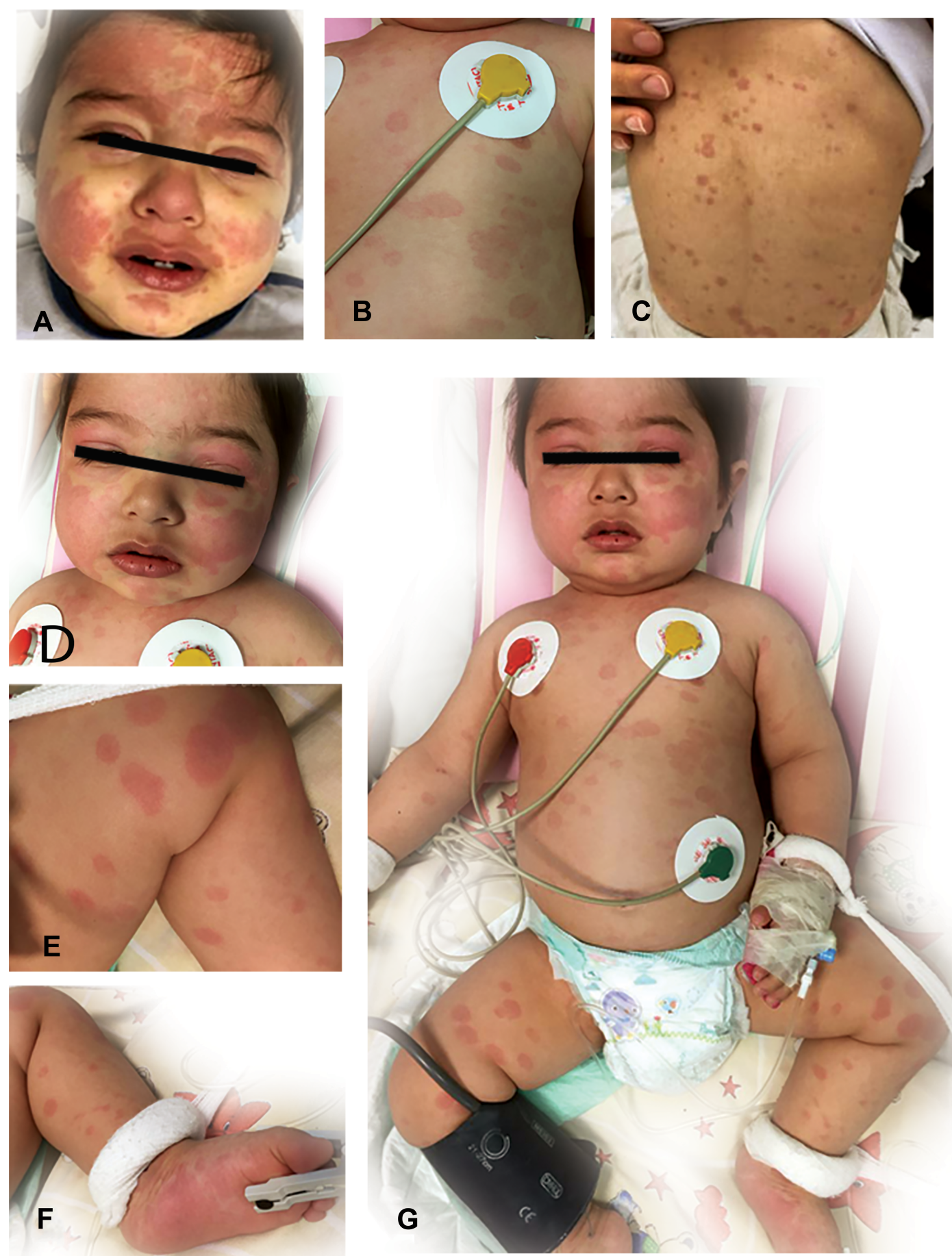

Figure I Dermatologic manifestations of the SARS-CoV-2 in infected infants. The facial rash on admission day (A); rashes on the face, trunk and exterimites on the second day of admission (B-G).

Echocardiography showed mild mitral valve regurgitation, and the coronary arteries were in the normal range.

On the third day, the patient was still febrile with the higher temperature detected (39-degree centigrade axillary), and his general health condition was still trending downward. The situation necessitated the administration of meropenem $(30 \mathrm{mg}$ per $\mathrm{kg}$ every 8 hours), instead of continuing ceftriaxone. The second lung HRCT scan showed patchy infiltration, pleural effusion, ground-glass opacity, and halo sign in both lungs. (Figure 2)

The chest sonography also showed bilateral moderate pleural effusion of the lungs. Abdominal sonography revealed normal intra-abdominal and pelvic organs. 
Table I Laboratory Results of the SARS-CoV-2 Infected Infant

\begin{tabular}{|c|c|c|c|c|c|c|c|c|c|c|c|}
\hline $\begin{array}{l}\text { Day of } \\
\text { Admission }\end{array}$ & $\begin{array}{l}\text { WBC } \\
(\times 106 / L)\end{array}$ & $\begin{array}{l}\text { NEUT } \\
\text { (\%) }\end{array}$ & $\begin{array}{l}\text { LYMPH } \\
\text { (\%) }\end{array}$ & $\begin{array}{l}\text { HGB } \\
\text { (g/dl) }\end{array}$ & $\begin{array}{l}\text { PLT } \\
(\times \mid 06 / L)\end{array}$ & $\begin{array}{l}\text { CRP } \\
(\mathrm{mg} / \mathrm{L})\end{array}$ & ESR & $\begin{array}{l}\text { Alb } \\
\text { (g/dl) }\end{array}$ & $\begin{array}{l}\text { BUN } \\
(\mathrm{mg} / \mathrm{dl})\end{array}$ & $\begin{array}{l}\mathrm{Cr} \\
\text { (mg/ } \\
\text { dl) }\end{array}$ & $\begin{array}{l}\text { BC } \\
\text { (BACTEC) }\end{array}$ \\
\hline Ist Day & 8200 & 65 & 29 & 10.8 & 189,000 & 96 & 54 & 3.4 & 528 & 0.7 & No Growth \\
\hline 3rd Day & 14,500 & 58 & 29 & 7.5 & $|4|, 000$ & 26 & 60 & 2.2 & 16 & 0.4 & NA \\
\hline 4th Day & 11,100 & 50 & 45 & 11.7 & 158,000 & NA & NA & 2.4 & NA & NA & NA \\
\hline
\end{tabular}

Abbreviations: WBC, white blood cells count; Neut, neutrophil; Lymph, lymphocyte; HGB, hemoglobin; PLT, platelet count; CRP, C reactive protein; ESR, estimated sedimentation rate (I hour); Alb, serum albumin; BUN, blood urea nitrogen; $\mathrm{Cr}$, serum creatinine; BC, blood culture; NA, not assessed.

A significant drop in hemoglobin necessitated the transfusion of packed red blood cells (10 milliliters per $\mathrm{kg}$ ). Evaluation for glucose 6 phosphate dehydrogenase deficiency, stool exam for occult blood, and coombs tests were not conclusive.

On the fifth day, general health condition improved, edema started to disappear, and skin rashes faded progressively without any remained hypo or hyperpigmented scar.

On the eighth day of admission, the patient was hospitalized at the pediatric infectious diseases ward, skin rashes were mostly disappeared, and edema was disappeared completely.

Finally, after more than 24 hours of stable clinical condition, the child was discharged on the 10th day of admission.

\section{Discussion}

Most of SARS-CoV-2 cases experienced fever, myalgia, dry cough, and respiratory illness at the onset of the disease. In children, the novel coronavirus mostly appears as a mild condition; however, in some cases causes fatal consequences. ${ }^{5,8}$

In the current case report, we described the SARS-CoV-2 in an infant who was presented with fever and rash without respiratory complaints at the onset of the disease accompanied by severe anemia, hypoalbuminemia, hypoxemia, and pleural effusion in the hospitalization period.

Dermatologic manifestations of the novel coronavirus infection are not rare during the illness. This is the first report of the simultaneous presentation of fever and rash as the initial presentation of SARS-CoV-2 in children.

Different skin lesions such as vesicular eruptions, pseudo chilblain, erythema multiform like lesions, palmar erythema, erythematous rash, etc. are observed in patients infected with COVID-19. ${ }^{6,9,12-14}$ In a report on adult patients, $20.4 \%$ (out of 88 patients) developed cutaneous lesions. ${ }^{9}$

Fever and rash were the first presenting symptoms in our case. Although information about the cutaneous manifestation of SARS-CoV-2 and its timing from the onset of the disease are clear in children, some studies conducted on adults reported the cutaneous manifestation as the first presentation of the COVID-19 (a study conducted on 88 adult patients, reported this presentation in $9 \%$ of participants). ${ }^{9}$

In an infant presented with fever and rash, differential diagnoses are viral exanthema, some bacterial infections, immunologic reactions, and rheumatologic diseases.

Our patient could not fulfill the criteria for toxic shock syndrome (TSS), and his blood culture (BACTEC) was negative.

In the absence of contact history and specific laboratory exam, leptospirosis, which is endemic in the north of Iran, was ruled out.

The coincidence of Kawasaki disease and SARS-CoV-2 is reported in some studies. ${ }^{10}$ Incomplete Kawasaki disease was in the differential diagnosis, but the diagnosis criteria were not fulfilled.

As reported in a study that investigated the coronavirus NL63, ${ }^{15}$ acute hemorrhagic edema of infancy is one of the first diagnoses. Although in the clinical course, it was found that this diagnosis is less accurate.

During the hospitalization, the child was complicated with generalized edema and hypoalbuminemia, which both are among the rare manifestations of coronavirus infection and their incidence is rarely reported in children. ${ }^{11}$ There are also some reports about MERS infection in adults, in which hypoalbuminemia was detected in the infected patients. ${ }^{16}$

No sign of intestinal or renal loss of protein was found in our case; Also, he did not have any background disease or failure to thrive. The question is, "what is the leading cause of hypoalbuminemia". It may be due to the cytokine storm, immunologic process, or vasculitis.

As the disease was progressing, the level of hemoglobin was significantly decreasing, which requires further investigation. Anemia is not common among children infected with SARS-CoV-2, although a case report mentioned to this issue. ${ }^{8}$ In the current study, the rapid 


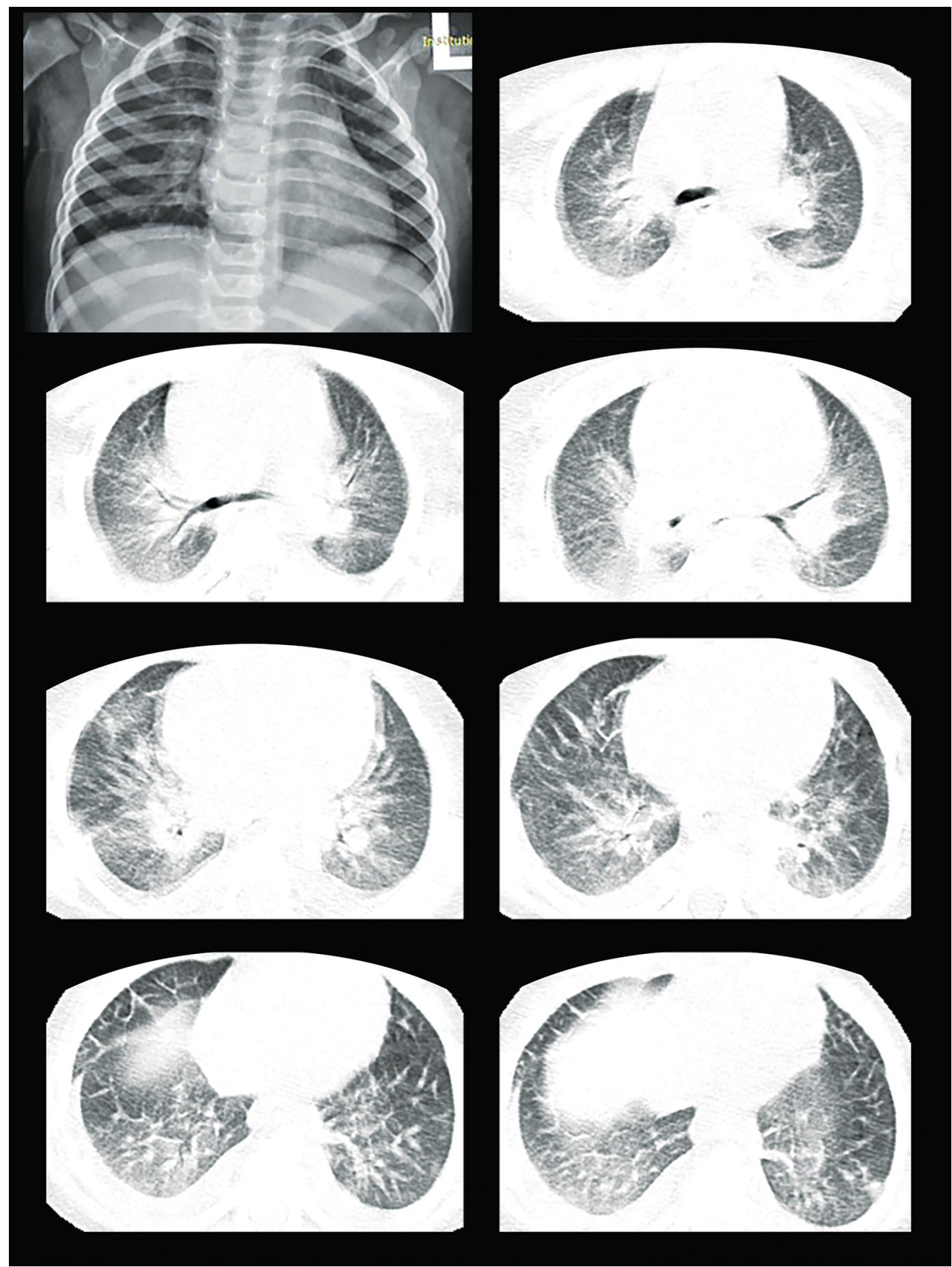

Figure 2 On admission chest X-ray and 3rd-day lung CT scan of infants infected with SARS-CoV-2.

decrease of hemoglobin concentration was simultaneous with the worsening of illness.

It may be a sign of acute intravascular hemolysis or microvascular thrombosis as a part of an immunologic reaction. ${ }^{11}$ Thus, we may attribute the anemia to the illness itself or immune-mediated anemia.
Pleural effusion is a rare manifestation of SARS-CoV-2, particularly in children. ${ }^{17,18}$ Our case was complicated because of significant pleural effusion, conversely.

Although it is presumed that the pleural effusion may be due to hypoalbuminemia, it may be a consequence of systemic inflammatory response. In complicated cases or 
for screening tests, an RT-PCR for SARS-CoV-2 can be helpful to have a better diagnosis. ${ }^{19}$

\section{Limitations}

Unfortunately, parents did not consent to take a biopsy of the skin lesions. Consequently, the exact pathological diagnosis for the lesions stays blurred.

\section{Conclusion}

This is the first announced case of an infected child with SARS-CoV-2 that had different manifestations, including fever, rash, anemia, anasarca edema, hypoalbuminemia, and pleural effusion. Understanding the exact reason for such presentations needs further investigation.

\section{Informed Consent}

Informed consent for publication was obtained from the patient's parent.

\section{Disclosure}

The authors declare no conflict of interest.

\section{References}

1. Ng O-T, Marimuthu K, Chia P-Y, et al. SARS-CoV-2 infection among travelers returning from Wuhan, China. $N$ Engl J Med. 2020;382 (15):1476-1478. doi:10.1056/NEJMc2003100

2. de Groot RJ, Baker SC, Baric RS, et al. Commentary: Middle East respiratory syndrome coronavirus (MERS-CoV): announcement of the Coronavirus Study Group. J Virol. 2013;87(14):7790-7792. doi:10.1128/JVI.01244-13

3. Zaki AM, Van Boheemen S, Bestebroer TM, Osterhaus ADME, Fouchier RAM. Isolation of a novel coronavirus from a man with pneumonia in Saudi Arabia. $N$ Engl $J$ Med. 2012;367 (19):1814-1820. doi:10.1056/NEJMoa1211721

4. Huang C, Wang Y, Li X, et al. Clinical features of patients infected with 2019 novel coronavirus in Wuhan, China. lancet. 2020;395 (10223):497-506. doi:10.1016/S0140-6736(20)30183-5

5. Cai J, Xu J, Lin D, et al. A Case Series of children with 2019 novel coronavirus infection: clinical and epidemiological features. Clin Infect Dis. 2020.
6. Henry D, Ackerman M, Sancelme E, Finon A, Esteve E. Urticarial eruption in COVID-19 infection. J Eur Acad Dermatol Venereol. 2020;34(6). doi:10.1111/jdv.16472

7. Xia W, Shao J, Guo Y, Peng X, Li Z, Hu D. Clinical and CT features in pediatric patients with COVID-19 infection: different points from adults. Pediatr Pulmonol. 2020;55(5):1169-1174. doi:10.1002/ppul. 24718

8. Rahimzadeh G, Ekrami Noghabi M, Kadkhodaei Elyaderani F, et al. COVID-19 infection in Iranian children: a case series of 9 patients. J Pediatr Rev. 2020;8(2):139-144. doi:10.32598/jpr.8.2.139

9. Recalcati S. Cutaneous manifestations in COVID-19: a first perspective. J Eur Acad Dermatol Venereol. 2020;34(5). doi:10.11 $11 / \mathrm{jdv} .16387$

10. Jones VG, Mills M, Suarez D, et al. COVID-19 and kawasaki disease: novel virus and novel case. Hosp Pediatr. 2020;hpeds: 2020-2123.

11. Riphagen S, Gomez X, Gonzalez-Martinez C, Wilkinson N, Theocharis P. Hyperinflammatory shock in children during COVID-19 pandemic. lancet. 2020;395(10237):1607-1608. doi:10.1016/S0140-6736(20)31094-1

12. Galván CC, Català A, Carretero HG, et al. Classification of the cutaneous manifestations of COVID -19: a rapid prospective nationwide consensus study in Spain with 375 cases. Br J Dermatol. 2020;183(1):71-77. doi:10.1111/bjd.19163

13. Estébanez A, Pérez-Santiago L, Silva E, Guillen-Climent S, GarcíaVázquez A, Ramón MD. Cutaneous manifestations in COVID-19: a new contribution. J Eur Acad Dermatol Venereol. 2020;34(6). doi: $10.1111 /$ jdv. 16474

14. Landa N, Mendieta-Eckert M, Fonda-Pascual P, Aguirre T. Chilblainlike lesions on feet and hands during the COVID-19 pandemic. Int J Dermatol. 2020;59(6):739-743. doi:10.1111/ijd.14937

15. Chesser H, Chambliss JM, Zwemer E. Acute hemorrhagic edema of infancy after coronavirus infection with recurrent rash. Case Rep Pediatr. 2017;2017.

16. Saad M, Omrani AS, Baig K, et al. Clinical aspects and outcomes of 70 patients with Middle East respiratory syndrome coronavirus infection: a single-center experience in Saudi Arabia. Int $J$ Infect Dis. 2014;29:301-306. doi:10.1016/j.ijid.2014.09.003

17. Bernheim A, Mei X, Huang $M$, et al. Chest CT Findings in Coronavirus Disease-19 (COVID-19): relationship to duration of infection. Radiology. 2020;295(3):200463. doi:10.1148/radiol.20202 00463

18. Ng M-Y, Lee EY, Yang J, et al. Imaging profile of the COVID-19 infection: radiologic findings and literature review. Radiology. 2020;2 (1):e200034.

19. Bwire GM, Paulo LS. Coronavirus disease-2019: is fever an adequate screening for the returning travelers? Trop Med Health. 2020;48 (1):1-3. doi:10.1186/s41182-020-00201-2
International Medical Case Reports Journal

\section{Publish your work in this journal}

The International Medical Case Reports Journal is an international, peer-reviewed open-access journal publishing original case reports from all medical specialties. Previously unpublished medical posters are also accepted relating to any area of clinical or preclinical science. Submissions should not normally exceed 2,000 words or 4 published pages including figures, diagrams and references. The manuscript management system is completely online and includes a very quick and fair peer-review system, which is all easy to use. Visit http://www.dovepress.com/testimonials.php to read real quotes from published authors. 